\title{
Arte y ciencia en el diagnóstico de la enfer- medad periodontal atípica: reporte de caso
}

\section{Art and science in the diagnosis of atypical periodontal disease: case report}

\author{
L. V. Maita Véliz*, M. Castañeda Mosto**, L. M. Maita Castañeda***, \\ U. Rivas Almonte***, D. Ramos Perfecto****
}

\section{RESUMEN}

Las lesiones pulpares y periodontales son las más prevalentes en la cavidad bucal y, tal vez por ello, son las causas más frecuentes de consulta odontológica en nuestro medio y en el mundo. Estas patologías tienen principalmente, etiología bacteriana y una flora polimicrobiana. Las estructuras anatómicas e histológicas de los tejidos periodontales y pulpares presentan interrelaciones, que deben considerarse en la etiopatología de sus procesos. El diagnóstico de las lesiones endoperiodontales no siempre se puede definir claramente, lo cual crea vacíos que dificultan el diagnóstico de las enfermedades pulpares y periodontales. El odontólogo debe estar preparado y entrenado para que le sea posible definir el diagnóstico diferencial de las dos enfermedades y brindar un tratamiento eficiente. Se reporta un caso clínico, donde el manejo del examen clínico, así como de la anatomía endoperiodontal, son decisivos para llegar al diagnóstico correcto y el tratamiento oportuno y adecuado.

PALABRAS CLAVE: Diagnóstico clínico; enfermedades periodontales; absceso periodontal; tratamiento (fuente: DeCS BIREME).

\section{ABSTRACT}

Pulp and periodontal lesions are the most prevalent in the oral cavity, and are the most frequent causes of dental consultation in our environment and in the world. These pathologies are mainly of bacterial etiology, with a polymicrobial flora. The anatomical and histological structures of the periodontal and pulp tissues present interrelationships that must be taken into account in the etiopathology of these processes. The diagnosis of endoperiodontal lesions is not always clearly defined, which constitutes certain gaps for the diagnosis. The dentist must be trained to perform the differential diagnosis of these two diseases and provide efficient treatment in our patients. A clinical case is reported, where the management of the clinical examination as well as the endoperiodontal anatomy is important to reach the correct diagnosis and its subsequent treatment.

KEY WORDS: Clinical diagnosis; periodontal diseases; periodontal abscess; treatment (source: MeSH NLM).

Fecha de recepción: 31 de diciembre de 2020

Fecha de aceptación: 05 de febrero de 2021

L. V. Maita Véliz, M. Castañeda Mosto, L. M. Maita Castañeda, U. Rivas Almonte, D. Ramos Perfecto. Arte y ciencia en el diagnóstico de la enfermedad periodontal atípica: reporte de caso. 2021; 37, (2): 78-86.

* $\quad$ Facultad de Odontología. Universidad Nacional Mayor de San Marcos. Lima, Perú. Doctor en Odontología. Cirujano Dentista.

* * Facultad de Odontología. Universidad Nacional Mayor de San Marcos. Lima, Perú. Cirujano Dentista.

*** Facultad de Odontología. Universidad Nacional Mayor de San Marcos. Lima, Perú. Magister en Estomatología. Cirujano Dentista.

**** Facultad de Odontología. Universidad Nacional Mayor de San Marcos. Lima, Perú.Doctor en Estomatología. Cirujano Dentista. 


\section{INTRODUCCIÓN}

Lograr el diagnóstico correcto es el mayor desafío para el clínico en el universo de las ciencias de la salud. ${ }^{1}$

Es así porque el diagnóstico es el proceso más enigmático que debe enfrentar cualquier clínico con cada nuevo paciente y es crucial para despejar el camino hacia la salud, toma tiempo y jamás debe ser asumido con prisa. ${ }^{1}$

Más aún, cuando hallamos que los signos y síntomas son ambiguos y no nos ayudan a establecer un diagnóstico definitivo y seguro.

En los casos como el que presentamos, realizar el diagnóstico diferencial de cada una de las dos enfermedades resulta, a veces, muy arduo y casi imposible porque las áreas y los tejidos biológicos, donde se desarrollan estos procesos patológicos, se encuentran en lugares muy ocultos, al interior de los maxilares, y no basta la sola percepción de los sentidos para evaluarlos. $^{2}$

En cuanto al diagnóstico diferencial, el odontólogo, por lo general no puede determinar con exactitud el estado pulpar patológico, desde un punto de vista clínico. No obstante, analizando los signos, los síntomas, la historia dental pasada y los hallazgos objetivos, consigue ubicar una probable categoría en el diagnóstico. ${ }^{3}$

En los casos en que están presentes, a la vez, lesiones periodontales y pulpares, también llamadas endoperiodontales, el proceso de diagnóstico se torna bastante intrincado y casi inescrutable por lo que constituye una verdadera prueba de percepción y tenacidad dar con la definición acertada.

\section{Consideraciones Anatómicas}

La pulpa y el periodonto están estrechamente relacionados por tres significativas vías anatómicas de comunicación: los túbulos dentinarios, los conductos laterales $\mathrm{y} / \mathrm{o}$ accesorios y el foramen apical. ${ }^{4-6}$

\section{Túbulos dentinarios}

Los túbulos dentinarios expuestos en espacios de cemento denudado pueden convertirse en vías de comunicación entre la pulpa y el ligamento periodontal. La exteriorización de los túbulos dentinarios podría ser resultado de defectos del desarrollo, trastornos o tratamientos periodontales. En la raíz, los tú- bulos dentinarios se extienden desde la pulpa hasta la unión entre la dentina y el cemento. Su trayecto es recto y su diámetro es de 1-3 um. Este diámetro disminuye con la edad o como respuesta a estímulos continuados de baja intensidad, por la aposición de dentina peritubular en gran medida mineralizada. La cantidad de túbulos dentinarios oscila aproximadamente $8,000 / \mathrm{mm}^{2}$ en la unión cemento dentinaria, a 57,000/mm $\mathrm{m}^{2}$ en el extremo pulpar. En la zona cervical de la raíz hay unos $15,000 / \mathrm{mm}^{2}$. Las personas que experimentan hipersensibilidad dentinaria cervical son un ejemplo de este fenómeno. Estudios elaborados, mediante microscopía electrónica de barrido, han demostrado que la exposición de dentina en la unión amelocementaria (UAC) se produce en el $18 \%$ de los dientes, en general, y en el $25 \%$ de los dientes anteriores, en particular. Además, el mismo diente, en ocasiones, llega a tener una UAC con diferentes características: zonas con exposición dentinaria en un lado y zonas cubiertas por cemento en otro lado. Otras vías de comunicación dentinaria pueden ser los surcos del desarrollo, tanto palatogingivales como apicales. ${ }^{1,5}$

\section{Conductos laterales y accesorios}

Los conductos laterales y accesorios pueden encontrarse en cualquier lugar a lo largo de la raíz. Se estima que el $30-40 \%$ de los dientes poseen conductos laterales o accesorios y la casi totalidad de ellos se encuentran en el tercio apical de la raíz. De Deus observó que el $17 \%$ de los dientes tenían conductos laterales en el tercio apical de la raíz, el $9 \%$ en el tercio medio, y menos del $2 \%$ en el tercio coronal. ${ }^{7}$ Castañeda M.M. halló 58,2\% deltas apicales y 31,3\% de conductos colaterales en los primeros premolares inferiores. ${ }^{8,9}$ Los conductos accesorios en la furca de los molares pueden ser una vía directa de comunicación entre la pulpa y el periodonto. La presencia de conductos accesorios varía entre el 23 y el $76 \% .^{5}$

\section{Foramen apical}

El orificio apical es la vía de comunicación principal y más directa entre la pulpa y los tejidos periodontales. Los productos bacterianos e inflamatorios pueden escapar libremente por el orificio apical y producir patología periapical. El ápex es también la puerta de entrada de los productos de la inflamación procedentes de bolsas periodontales profundas hacia la pulpa. ${ }^{5}$

\section{Enfermedad pulpar y periodonto}

Cuando la pulpa se necrosa, hay una respuesta inflamatoria directa en el ligamento periodontal a nivel del agujero apical y/o de la salida de los conductos 
accesorios. Elementos inflamatorios de origen pulpar, pueden deslizarse a través del ápex, los canales laterales y accesorios desencadenando una respuesta vascular inflamatoria en el periodonto. Entre éstos hay patógenos vivos, como bacterias y sus toxinas, incluyendo hongos y virus. Muchos de ellos son similares a los patógenos hallados en las infecciones periodontales. ${ }^{10}$

Con relación a la microbiología de las lesiones endoperiodontales, se ha podido aislar una flora periodontal infecciosa con diversos microorganismos como los del complejo rojo (Porphyromas gingivales ${ }^{11}$, Tannerella forsythia ${ }^{12}$, Treponema ${ }^{13}$ ) y del complejo naranja (Fusobacteroium, Prevotella). Otros como Parvimonas micra. Mediante técnicas moleculares, se ha logrado aislar una flora bacteriana poco común, destacando las siguientes especies: Filifactor alocis, Enterococcus fecalis y de los géneros Desulfobulbus, Dialister. ${ }^{14,15}$ Estudios recientes de metagenómica de la microbiota del absceso periodontal, susceptible de aparecer en una lesión endoperiodontal, subrayan la presencia de una flora no usual, como Filifactory Atopobium rimae. ${ }^{15}$

El efecto de la inflamación periodontal sobre la pulpa es un tema polémico y abundan las investigaciones con resultados contradictorios. Se ha sugerido que la enfermedad periodontal no tiene consecuencia sobre la pulpa, al menos hasta que dañe al ápex. Por otra parte, varios estudios señalan que el efecto de la enfermedad periodontal en la pulpa es degenerativo por naturaleza: aumento de la calcificación, fibrosis y resorción del colágeno, así como una consecuencia inflamatoria directa.

Si bien es cierto que las afecciones endoperiodontales presentan una incidencia baja, conllevan alta mortalidad dental, debido precisamente al daño periodontal. ${ }^{10}$

\section{Diagnóstico diferencial}

Para el diagnóstico diferencial de las lesiones endoperiodontales, es mejor clasificarlas como enfermedades pulpares, enfermedades periodontales y enfermedades combinadas. Estas afecciones comprenden: enfermedad pulpar primaria, enfermedad periodontal primaria y las siguientes enfermedades combinadas: enfermedad pulpar primaria con afectación periodontal secundaria, enfermedad periodontal primaria con afectación pulpar secundaria y enfermedades combinadas verdaderas..$^{5,14,16-19}$

\section{Enfermedad pulpar primaria}

Una exacerbación aguda de una lesión apical crónica con pulpa necrótica puede drenar coronalmente a través del ligamento periodontal hasta el surco gingival. Esta situación puede parecerse clínicamente a un absceso periodontal. En realidad, es una fístula de origen pulpar que atraviesa el área del ligamento periodontal. Para el diagnóstico, es imperativo que el clínico inserte una punta de gutapercha en el trayecto de la fístula y tome una o más radiografías para descubrir el origen de la lesión. Cuando se utiliza la sonda peridontal para evaluar la bolsa formada, se aprecia que es estrecha y no tiene anchura. Una situación similar se da cuando el drenaje desde el ápex de un molar se extiende coronalmente al área de furcación. Esto puede pasar cuando hay presencia de conductos laterales que extienden desde una pulpa necrótica al área de furcación. ${ }^{5,17,18}$

\section{Enfermedad periodontal primaria}

La enfermedad periodontal primaria se debe sobre todo a los patógenos periodontales. En este proceso, la periodontitis crónica progresa apicalmente a lo largo de la superficie radicular. En la mayoría de los casos, las pruebas pulpares indican una reacción pulpar normal. Por lo común, existe acumulación de placa y cálculo, y las bolsas son más anchas que en la enfermedad pulpar primaria. ${ }^{5,14,16}$

\section{ENFERMEDADES COMBINADAS}

\section{Enfermedad pulpar primaria con afectación perio- dontal secundaria}

Si una enfermedad pulpar supurante permanece sin tratar durante cierto tiempo, puede provocar destrucción periodontal secundaria. Se forma placa en el borde gingival del trayecto de la fístula, que deviene en periodontitis inducida por placa en esa área. Cuando se detecta placa o cálculo, el tratamiento y el pronóstico del diente difieren de cuando los dientes han contraído solo enfermedad pulpar primaria. En estos casos, el diente requerirá tratamiento endodóncico y periodontal. Si el tratamiento endodóntico es adecuado, el pronóstico dependerá de la gravedad de la periodontitis inducida por placa y de la eficacia del tratamiento periodontal. Si se hace solo tratamiento endodóntico, se solucionará solo la lesión pulpar, es decir, hasta el nivel de la lesión periodontal secundaria. Las lesiones pulpares primarias con afectación periodontal secundaria también pueden producirse como consecuencia de perforación de la raíz, durante el tratamiento de conductos, o de colocación inco- 
rrecta de postes o pines, durante la restauración de coronas. Los síntomas pueden ser agudos con brote de abscesos periodontales asociados a dolor, inflamación, pus o exudado y, en otros casos, con presencia de bolsas y movilidad del diente. Incluso dichas lesiones pueden darse de una forma crónica sin dolor y aparición súbita de una bolsa con sangrado durante el sondaje o con exudado de pus., 20

\section{Enfermedad periodontal primaria con afectación pulpar secundaria}

La progresión de una bolsa periodontal alcanza, incluso a afectar los tejidos apicales. En estos casos, la pulpa puede necrosarse como resultado de la infección que penetra por los canales laterales o el agujero apical. Hay controversia sobre el efecto de la progresión de la periodontitis crónica en la vitalidad de la pulpa. Si el aporte de sangre que circula a través del ápex está intacto, la pulpa tiene buenas expectativas de supervivencia. Está visto que los cambios pulpares debidos a enfermedad periodontal son más probables cuando está afectado el foramen apical. En estas circunstancias, las bacterias que se originan en la bolsa periodontal pueden ser una fuente de infección de los conductos radiculares con mayor facilidad. Se ha constatado una correlación significativa entre la presencia de microorganismos en los conductos radiculares y su existencia en las bolsas periodontales de la periodontitis avanzada. Este concepto es avalado por estudios que comprobaron el crecimiento bacteriano en el $87 \%$ de las muestras de tejido pulpar y dentina radicular de dientes humanos afectados de periodontitis. ${ }^{5,17}$

La afectación pulpar secundaria también puede ser provocada por el tratamiento de la enfermedad periodontal. Los conductos laterales y los túbulos dentinarios pueden abrirse en la cavidad bucal por el raspado y alisado radiculares o por cirugía de colgajo. Si un vaso sanguíneo de un conducto lateral se rompe en el raspado, los microorganismos entran en esa zona durante el proceso e inducen inflamación y necrosis de la pulpa. ${ }^{5,16,17}$

\section{Enfermedad combinada verdadera}

Se origina cuando una lesión pulpar en su avance hacia el área coronal, se encuentra con otro proceso patológico independiente identificado como bolsa periodontal la que avanza en sentido apical y luego se unen estas dos enfermedades para denominarse: enfermedad combinada verdadera.

\section{Procedimientos de diagnóstico clínico}

Las pruebas clínicas son ineludibles para el correcto diagnóstico y para la diferenciación entre enfermedad pulpar y enfermedad periodontal. Se han de explorar los tejidos extraorales e intraorales para detectar cualquier anomalía o indicio de enfermedad. Una sola prueba no suele ser suficiente para establecer un diagnóstico concluyente. ${ }^{5,14,17,21,22}$

Las pruebas deben incluir los siguientes aspectos:

- Examen clínico.

- Palpación.

- Percusión.

- Movilidad.

- Examen radiológico.

- Pruebas de vitalidad pulpar.

- Prueba de la cavidad.

- Pruebas en dientes restaurados.

- Sondaje periodontal.

- Trayecto de la fístula.

- Uso de transiluminación.

- Mordida.

- Tinción.

-Prueba de anestesia selectiva.

\section{REPORTE DEL CASO CLÍNICO}

Consulta inicial: Paciente de 25 años, varón, estudiante universitario acude a un odontólogo porque siente dolor en la región de los incisivos centrales superiores, piezas 11 y 21 , desde hace dos semanas aproximadamente, siendo el dolor más intenso en la noche. El dentista le indica una radiografía y luego le informa que su estado dental no muestra alteraciones y lo encuentra normal. Asocia el dolor a un golpe antiguo y le receta analgésicos.

Después de 2 a 3 días de este episodio, el paciente vuelve a consulta por que el dolor se ha hecho más intenso y percibe una tumefacción que va creciendo y ya dura aproximadamente 4 días. El profesional le recomienda nuevamente analgésicos y además un antibiótico por vía oral. Le menciona, como alternativa, un tratamiento de endodoncia.

Tercera consulta: el dolor continúa y la hinchazón es mucho mayor por lo que el paciente acude a otro odontólogo quien le prescribe megacilina inyectable cada 12 horas por 5 días. La hinchazón disminuye considerablemente y queda una "bola" (bulto) en la región incisal superior. Posteriormente, al cesar el efecto del antibiótico, aparece una nueva tumefacción por lo que es derivado a nuestra consulta. 


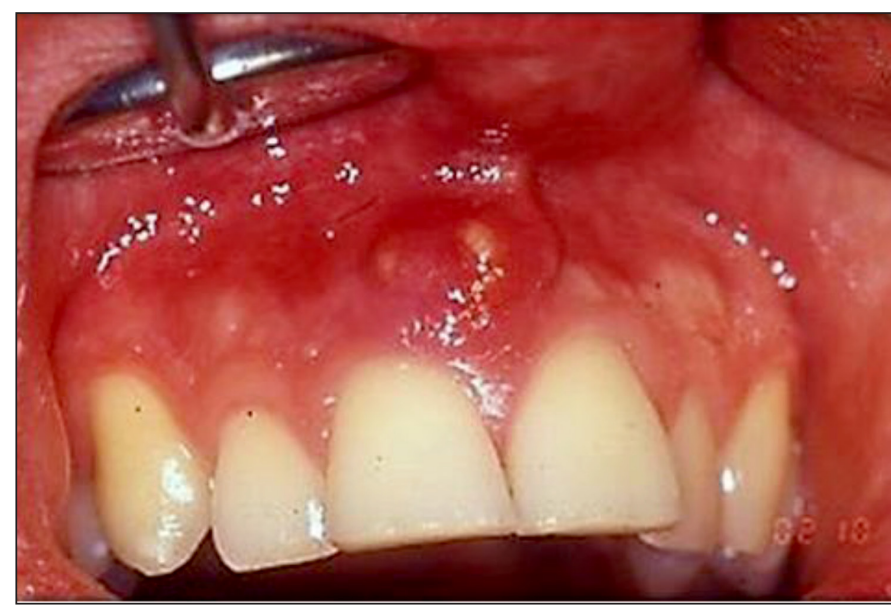

Fig. 1. Lesión, tipo absceso, ubicada en la línea media, tiene aproximadamente $10 \mathrm{~mm}$ de diámetro, depresible y fluctuante. No se detecta bolsa periodontal en las caras vestibulares y palatinas de las piezas 11 y 21 . No hay caries dental en estas piezas dentales.

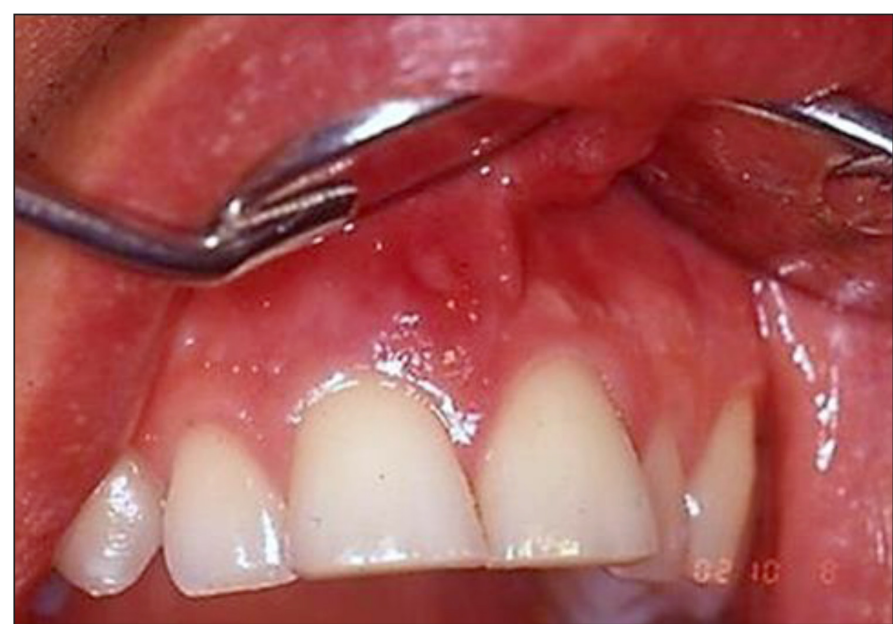

Fig. 3. Transcurridos 3 días de la ingesta de antibióticos, la lesión remite.

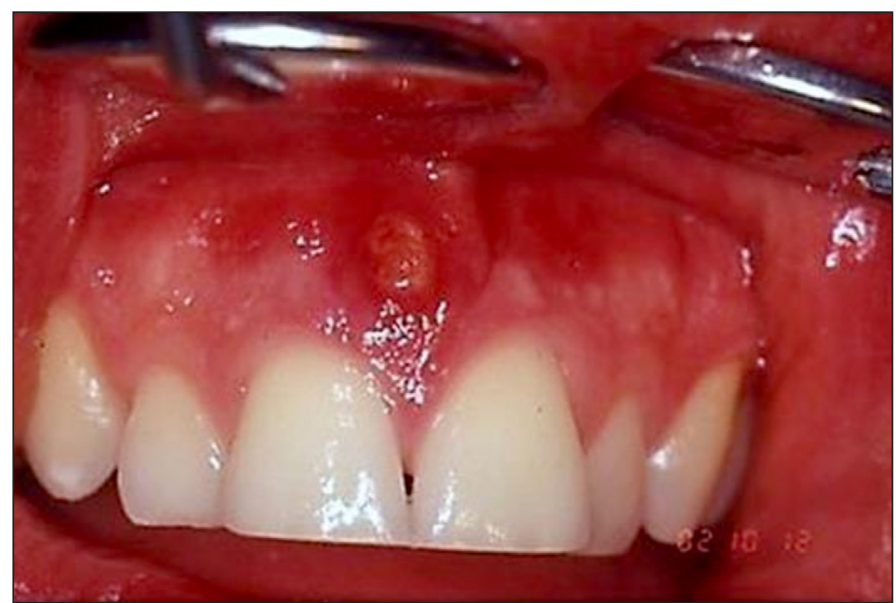

Fig. 4. Pasados 7 días de la consulta inicial, se presenta nuevamente la tumefacción en el mismo lugar.

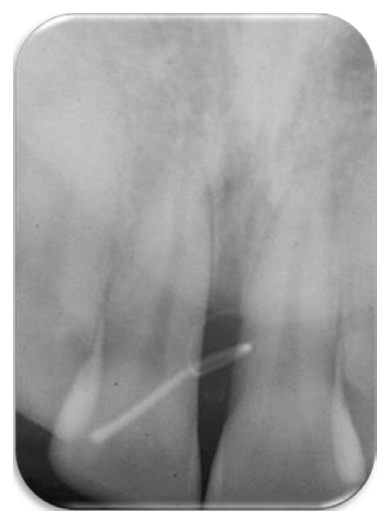

Fig. 2. Imagen de la fistulografía. El cono de gutapercha se dirige a la línea media. Se nota reabsorción ósea interproximal en el tercio cervical. No se observa caries dental en las coronas de estas piezas.

\section{la pieza 11, una tumefacción que es fluctuante de} la pieza 11 , una tumefacción que es fluctuante y depresible. Ante la palpación manual, el paciente manifiesta ligero dolor. Este absceso se localiza a nivel de la línea media (Fig. 1).

Se realiza pruebas de vitalidad pulpar en las piezas dentales 11, 12, 13, 21 y 22, todas responden instantáneamente al frío y a calor. A la percusión vertical, se escucha un sonido normal y ninguna molestia en las piezas 11, 12, 21 y 22. A la percusión horizontal, tampoco refiere molestias en estas piezas dentales.

Examen periodontal: los tejidos periodontales no muestran alteraciones ni áreas de inflamación. Al sondaje periodontal, los parámetros clínicos de profundidad de sondaje y nivel de inserción están dentro de los rangos normales.

Examen radiográfico: A fin de averiguar el origen de la lesión, se realiza una fistulografía empleando un cono de gutapercha dirigido hacia la línea media (Fig. 2), entre los dos incisivos superiores centrales. Examinando la radiografía, se advierte una reabsorción ósea interproximal entre las piezas 11 y 21 .

Como medida inicial se dispone que continúe con la terapia antibiótica que ya tenía prescrito. El efecto es visible a los tres días, cuando la lesión abscedosa remite y aparentemente desaparece (Fig. 3).

Cuando cesa el efecto del antibiótico, la lesión vuelve aparecer (Fig. 4). 


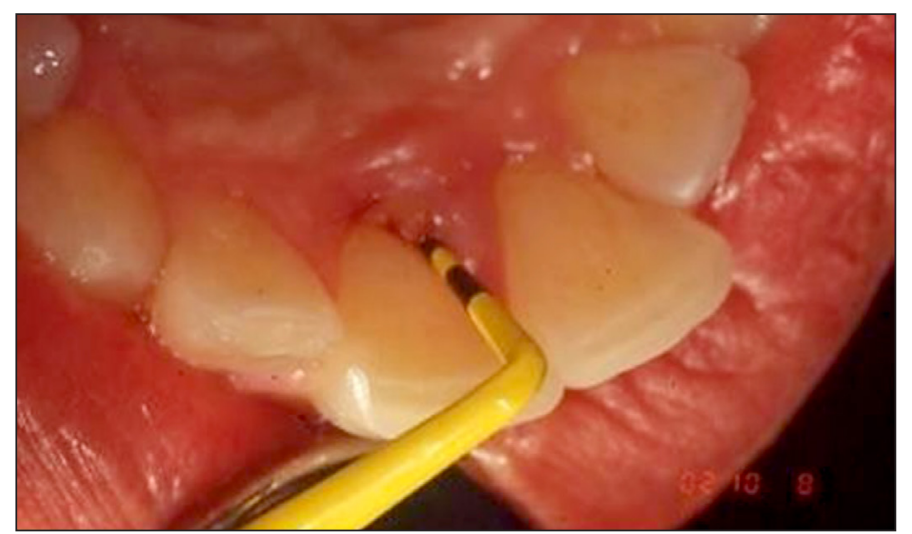

Fig. 5. Después de varias y repetidas evaluaciones periodontales de la pieza11, se encontró en la cara palatina una profundidad de sondaje en 4,5 $\mathrm{mm}$.

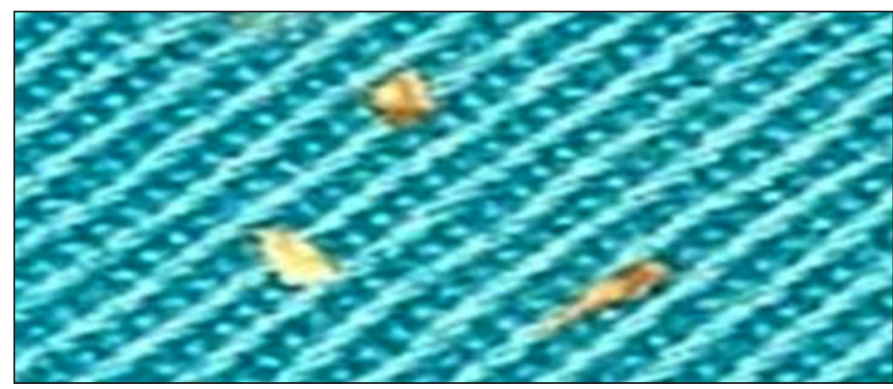

Fig. 6. Pequeñas formaciones de tártaro subgingival hallados una semana después de la consulta inicial.

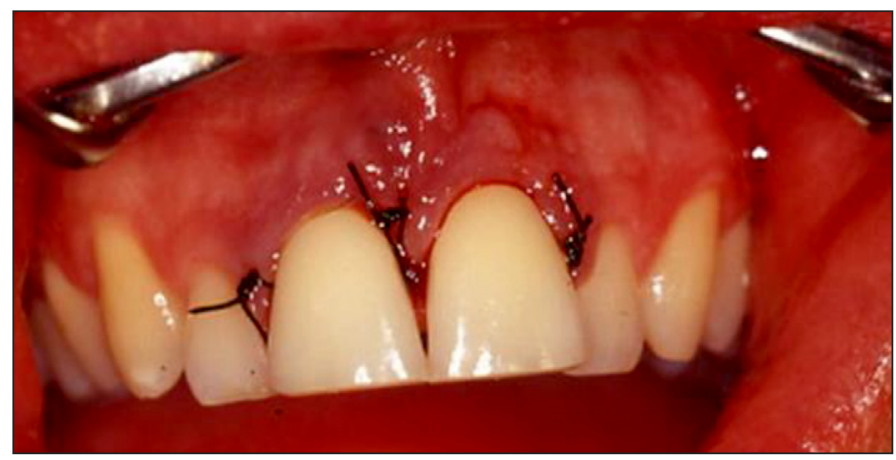

Fig. 7. Tras 12 días de la consulta inicial, se realizó un colgajo periodontal mucoperióstico.

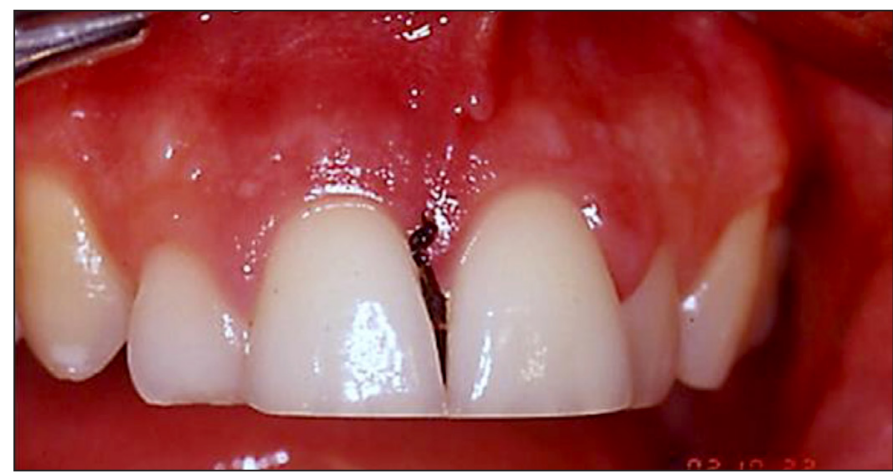

Fig. 8. Luego de una semana de la cirugía periodontal, nótese la excelente cicatrización.
En días sucesivos, se afectúan varios sondajes periodontales hallándose una bolsa periodontal de 4,5 $\mathrm{mm}$ en la cara palatina hacia el lado mesial de la pieza 11 (Fig. 5) y también, en la misma área, tártaro subgingival (Fig. 6). Un detalle muy significativo y, que concita la atención, es la no existencia de bolsa periodontal en la cara vestibular de la pieza 11.

Examen de laboratorio: El hemograma, el tiempo de coagulación y el tiempo de sangría se encuentran dentro de los rangos normales.

\section{Diagnóstico}

El análisis de la información obtenida y de los exámenes correspondientes, no era suficiente para llegar a un diagnóstico. Hasta ese momento, habíamos descartado que fuera un problema de oclusión, una alteración de la articulación temporomaxilar, una patología tumoral maxilar, tampoco había indicios de una patología sistémica. Nuestra opinión, basada en el hallazgo del tártaro subgingival (Fig. 6), es que se trata de una lesión periodontal aguda atípica, a pesar de no percibir una bolsa periodontal de gran profundidad, no producirse sangrado espontáneo, ni tampoco secreción purulenta. Por todas estas consideraciones, se decide llevar a cabo una exploración quirúrgica periodontal.

\section{Plan de tratamiento}

Se administró anestesia infiltrativa en el área vestibular y palatina de la zona anterosuperior, cerca de la línea media. Se diseñó un colgajo periodontal de espesor total para abarcar las piezas 12, 11, 21, 22. Se tuvo el mayor cuidado quirúrgico para decolar las papilas gingivales interproximales de las piezas dentarias antes señaladas, por la implicancia estética de los espacios interproximales.

Al practicar el colgajo en la cara mesial de la pieza 11, se observó tejido de granulación. Fue eliminado con las curetas periodontales anteriores Gracey 1-2 (Hu-Friedy, USA), finalizando con el raspador anterior Morse $\mathrm{N}^{\circ} 00$.

Después de extirpar todo el tejido de granulación, el colgajo fue reposicionado con mucho cuidado en su lugar y se suturó (Fig. 7). Se medicó con analgésicos y antibióticos y se le indico un enjuague bucal a base de clorhexidina al $0,12 \%$. 


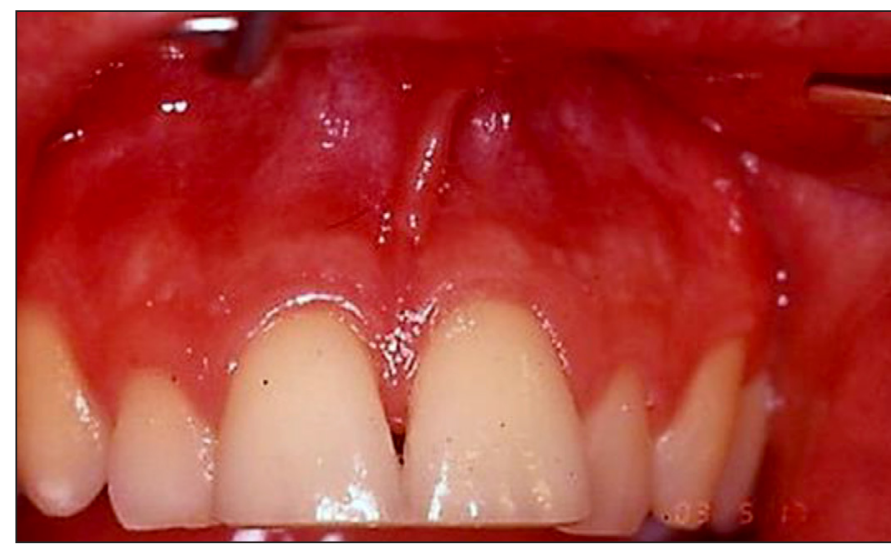

Fig. 9. Después de 7 meses del tratamiento periodontal, el paciente mantiene una buena salud periodontal.

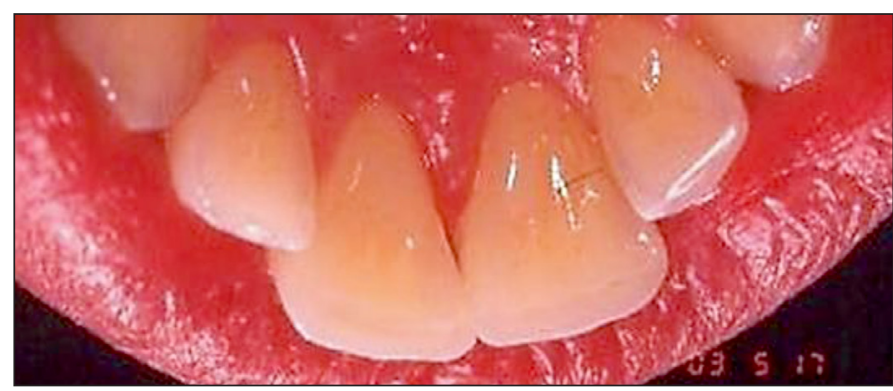

Fig. 10. Los tejidos periodontales de las caras palatinas de la figura 9 conservan también salud periodontal.

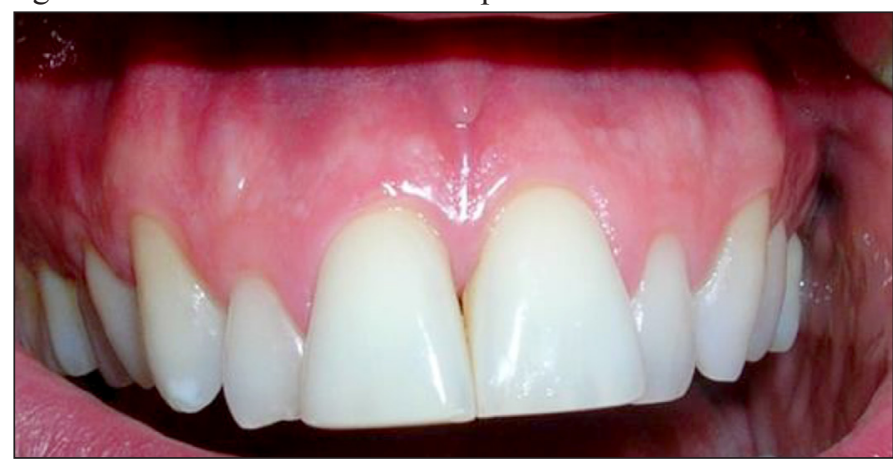

Fig. 11. Transcurridos 7 años de control: la salud de los tejidos periodontales es excelente.

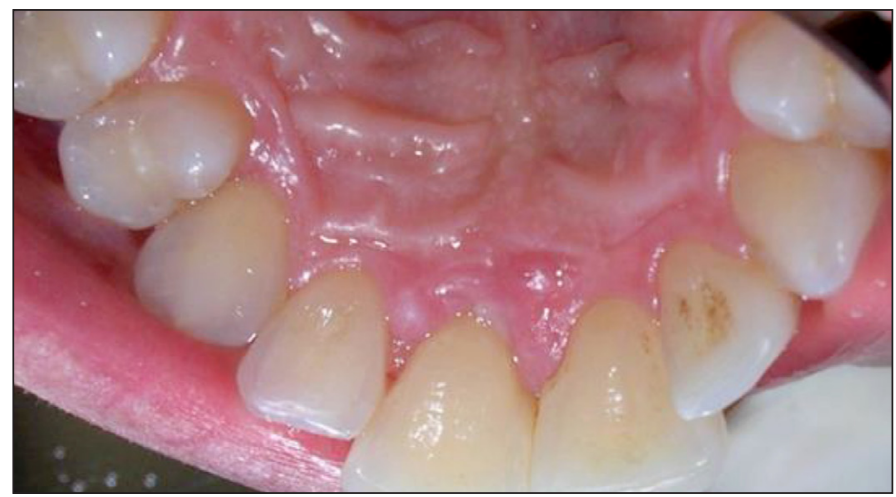

Fig. 12. Los tejidos periodontales de las caras palatinas de la figura 11 también muestran óptima salud periodontal.
Pasados 7 días, como se establece se retiró los 3 puntos (Fig. 8).

Las figuras 9 y 10 muestran la excelente evolución periodontal a los siete meses de control.

La evolución clínica de más de 7 años de control evidencia que el diagnóstico y el tratamiento periodontal fueron los correctos para este absceso periodontal agudo atípico (Fig. 11, 12 y 13).

\section{Discusión}

Se ha revisado la literatura dental y no se ha visto un caso clínico semejante como el que se presenta.

Este caso es único porque el absceso periodontal, de regular tamaño, se encontraba en la cara vestibular de la pieza 11 , muy distante de su origen: una bolsa periodontal incipiente (4,5mm de profundidad), ubicada en la cara palatina mesial de la pieza 11.

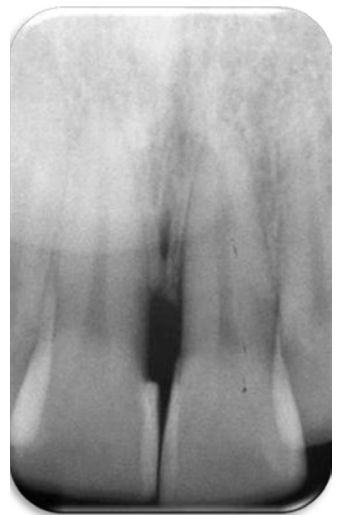

Fig. 13. Radiografía de control después de 7 años del tratamiento.
Clínicamente, este absceso periodontal, localizado sobre el tercio medio de la raíz vestibular de la pieza 11, daba la impresión inicial de ser compatible con un absceso de origen pulpar, en una pieza dental que no presenta caries dental y en un paciente con un estado de salud periodontal muy bueno.

Mientras el paciente estaba medicado con antibióticos el absceso periodontal desaparecía. Después del cese de la acción de los antibióticos el absceso volvía a presentarse (Fig. 4).

La microbiología de los abscesos periodontales ha sido ampliamente estudiada, aislándose en estos abscesos, más a menudo, patógenos periodontales, como Fusobacterium nucleatum, Peptostreptococcus micros, Porphyromonas gingivalis, Prevotella intermedia y Bacteroides Forsythus. ${ }^{23}$

Recordemos que el absceso periodontal es la tercera urgencia dental más frecuente, especialmente en pacientes periodontales no tratados y en pacientes periodontales durante la fase de mantenimiento. ${ }^{24}$ 
Sin embargo el caso que damos a conocer, no se refiere a un paciente periodontal no tratado, y tampoco era un paciente periodontal en mantenimiento.

Es dable sostener la hipótesis de que podrían existir medios anatómicos todavía no estudiados, con posibilidad de establecer vías de comunicación o anastomosis entre el área mesial de la pieza 11 con la cara vestibular de la misma pieza dentaria, que podrían explicar, de algún modo, la aparición de un absceso periodontal en la cara vestibular de la pieza 11. La bolsa periodontal de $4,5 \mathrm{~mm}$, al sondaje periodontal, no presentó secreción purulenta en ningún momento durante las fases de evaluación diagnóstica o de tratamiento periodontal.

\section{CONCLUSIONES}

1. En las enfermedades periodontales y pulpares, los procedimientos de diagnóstico son esenciales para dar con el diagnóstico correcto.

2. Establecer las diferencias entre las enfermedades periodontales y pulpares no siempre es sencillo, se dan vacíos en el proceso de diagnóstico.

3. La fisiología y patología de los procesos periodontales y pulpares debe ser objetivo de mayores investigaciones.

4. El correcto diagnóstico de las lesiones pulpares y/o periodontales posibilitarán un tratamiento exitoso.

El proceso de llegar al diagnóstico es, no solo ciencia sino arte..$^{25}$

El éxito requiere no solo talento, conocimientos y experiencia, sino el pensamiento intuitivo, la visión extrasensorial y la especial sensibilidad perceptiva que da el arte, sumados a una rigurosa concentración y meticulosidad en la tarea. ${ }^{26}$

Antes de terminar, quiero agregar unas palabras, como cuando el expositor, cerrado el tema, guarda su cuaderno de apuntes pero ya retirándose se detiene, tal vez demasiado enamorado de su ciencia, para compartir una reflexión última.

Así, mirándonos cara a cara, como maestro a discípulo, colega a colega, médico amigo a paciente, quiero incidir en que la dificultad más abrupta y ries- gosa que enfrentamos en cada caso es la asunción de diagnóstico, porque es decisoria y porque allí puede residir nuestra flaqueza.

Se dijo en el inicio que llegar al diagnóstico era un desafío, que el diagnóstico es crucial para establecer el camino hacia la salud pero, al mismo tiempo, es el proceso más enigmático de las ciencias médicas principalmente porque nos encontramos con vacíos en el proceso del diagnóstico.

Aquí podemos afirmar que llegar al diagnóstico es no solo ciencia sino un arte ${ }^{25}$.

Para subrayar repetimos que establecer el diagnóstico hace necesario observar desde el punto de vista clínico, analizar los signos, los síntomas, la historia dental pasada y los hallazgos objetivos. Pero además mirar un poco más allá, abarcando un espectro más amplio y, quizá por eso, más difuso.

Hace falta no solo deducir sino intuir, como diría un poeta: ver con los ojos del alma.

Alguien dijo: Para escribir una frase necesito apoyarme en una biblioteca. Desde esa ruta permítanme citar a Robert Root (Ph.D. profesor de Fisiología en la Universidad Estatal de Michigan-EE.UU.), como líneas finales: El proceso de adentrarse en cualquier disciplina suele ir acompañado de intensos sentimientos físicos y emocionales, expresados con frecuencia en términos auditivos, cinestésicos o visuales. Tales sentimientos no pueden separarse del acto mismo del descubrimiento. El intelecto no funciona sin la participación del individuo como totalidad; por eso la ciencia solo puede florecer en la mente de personas sensibles y emotivas. $(. . .)^{27}$

Al parecer, la mejor ciencia surge cuando se conjugan una mente analítica y una sensibilidad estética. (...)

Finalmente, como dijo el biólogo inglés C.H. Waddington, en 1969, "los graves problemas del mundo solo podrán ser resultados por hombres completos, no por quienes se nieguen a ser públicamente algo más que tecnólogos, científicos puros $\mathrm{o}$ artistas. En el mundo de hoy se tiene que ser de todo o no se es nada". ${ }^{27}$

\section{AGRADECIMIENTO}

A la Profesora Mg. Lily Cardich por la diligente revisión 
de estilo del manuscrito original y sus valiosos aportes.

\section{REFERENCIAS BIBLIOGRÁFICAS}

1. Lozada NF. El arte de diagnosticar: el dilema del clínico. Rev Oral B News. 2013; 1(1):16-20.

2. Bergenholtz G, Hørsted-Bindsley P, Reit C. Endodoncia. 2a ed. México: Editorial Manual Moderno; 2011.

3. Bender IB, Seltzer S. The effect of periodontal disease on the pulp. Oral Surg Oral Med Oral Pathol. 1972; 33(3):458-74. doi: 10.1016/0030-4220(72)90476-8.

4. Foce E. Endo-Perioodontal Lesions. 1a ed. Italia: Quintessence Publishing; 2011.

5. Rotstein I, Simon JH. Diagnosis, prognosis and decision-making in the treatment of combined periodontal-endodontic lesions. Periodontol 2000. 2004; 34:165203. doi: 10.1046/j.0906-6713.2003.003431.x.

6. Maita VL., Castañeda M.M. Interrelaciones entre las enfermedades periodontales y pulpares. Odontología sanmarquina 2002; 1(9): 46-49.

7. De Deus QD. Frequency, location, and direction of the lateral, secondary, and accessory canals. J Endod. 1975; 1(11):361-6. doi: 10.1016/s0099-2399(75)80211-1.

8. Castañeda M.M. Aporte a la endodoncia en el estudio topográfico de las raíces y conductos del primer premolares inferior [Tesis de Bachiller]. [Lima]: Facultad de Odontología, Universidad Nacional Mayor de San Marcos; 1972.

9. Castañeda M.M.Peruvian Association of Dental Research 1st Annual Meeting December 9-10, 1991 Lima, Peru. J Dent Research. 1992; 71(4):1077-1080. doi:10.1177/00 220345920710040601

10. Rodríguez MT, Parejo MD, Mayán RG, Herrero HL, Velázquez $\mathrm{MC}$. Lesiones endoperiodontales y mortalidad dentaria. Rev haban cienc méd 2014;13(4):547-560. Disponible en: http://scielo.sld.cu/scielo.php?script=sci_arttextEpid=S1729-519X2014000400006Elng=es

11. Ramos-Perfecto D, Moromi-Nakata H, Martínez-Cadillo E. Porphyromonas gingivalis: patógeno predominante en la periodontitis crónica. Odontol Sanmarquina. 2011; 14(1):34-8. Disponible en: https://revistasinvestigacion. unmsm.edu.pe/index.php/odont/article/view/2907

12. Ramos-Perfecto D. Tannerella forsythia: patógeno importante en la periodontitis, integrante del complejo rojo. Odontol Sanmarquina. 2020;23(3):253-9. Disponible en: https://revistasinvestigacion.unmsm.edu.pe/index.php/ odont/article/view/18400

13. Ramos-Perfecto D, Ávila-Campos M, Levano-Torres V. Treponema denticola: patógeno en procesos periodontales y pulpares. Odontol Sanmarquina 2012; 15(2):38-1. Disponible en: https://revistasinvestigacion.unmsm.edu. pe/index.php/odont/article/view/2046

14. Herrera D, Retamal-Valdes B, Alonso B, Feres M. Acute periodontal lesions (periodontal abscesses and necrotizing periodontal diseases) and endo-periodontal lesions. J Periodontol. 2018; 89 Suppl 1:S85-S102. doi: 10.1002/ JPER.16-0642.

15. Chen J, Wu X, Zhu D, Xu M, Yu Y, Yu L, Zhang W. Microbiota in Human Periodontal Abscess Revealed by $16 \mathrm{~S}$ rDNA Sequencing. Front Microbiol. 2019; 10:1723. doi: 10.3389/fmicb.2019.01723.
16. Sanz-Sánchez I., Bascones-Martínez A.. Otras enfermedades periodontales. II: Lesiones endo-periodontales y condiciones y/o deformidades del desarrollo o adquiridas. Av Periodon Implantol. 2008; 20(1):67-77. Disponible en: http://scielo.isciii.es/scielo.php?script=sci_arttextEpid=S1699-65852008000100007Elng=es

17. Regidor E, Ortiz-Vegón A, Navarro J, Gross E. Lesiones endo-periodontales: diagnostico, clasificación, tratamiento y pronóstico. DM. 2019; 40:28-36. Disponible en: https://www.eldentistamoderno.com/wp-content/ uploads/pdf/DM40-pag28-37.pdf

18. Pesqueira P, Carro H. Lesiones endoperiodontales. Odontología Vital. 2017; 27:35-44. Disponible en: http://www. scielo.sa.cr/scielo.php?script=sci_arttextEpid=S1659 $07752017000200035 \varepsilon$ ing $=$ en

19. Al-Fouzan KS. A new classification of endodontic-periodontal lesions. Int J Dent. 2014; 2014:919173. doi: 10.1155/2014/919173.

20. Jivoinovici R, Suciu I, Gheorghiu I, Suciu I. Clinical radiological aspects of primary endodontic lesions with secondary periodontal involvement. J Med Life. 2017; 10(1):70-75

21. Marañon G. La medicina y los médicos. 1a ed. España: Editorial Calpe; 1962

22. Gutmann J, Lovdahl P. Solución de Problemas en Endodoncia. 5a ed. España: Elsevier Mosby; 2012.

23. Herrera D, Roldán S, González I, Sanz M. The periodontal abscess (I). Clinical and microbiological findings. J Clin Periodontol. 2000;27(6):387-94. doi: 10.1034/j.1600051x.2000.027006387.x.

24. Herrera D, Roldán S, Sanz M. The periodontal abscess: a review. J Clin Periodontol. 2000;27(6):377-86. doi: 10.1034/j.1600-051x.2000.027006377.x.

25. Hangreaves K \& Goodis H. Seltzer and Bender's Dental Pulp. 1a ed. USA: Quintessence Publishing; 2002.

26. Marsh H. Ante todo, no hagas daño. $1^{\text {a }}$. ed. España: Ediciones Salamandra, 2016

27. Root-Bernstein R. Como descubrir el arte en la ciencia. Rev. Facetas. 1991;92:44-7.

\section{DIRECCIÓN DE CORRESPONDENCIA:}

Luis Maita Véliz. Correo electrónico:

lmaitav@unmsm.edu.pe

Dirección: Calle Vargas Machuca 194-Lima 18,

Perú

Coautor:

María Castañeda Mosto:

mcastanedam@unmsm.edu.pe

L. Mariano Maita Castañeda:

Imaitac@unmsm.edu.pe

Ursula Rivas Almonte:

urivasa@unmsm.edu.pe

Donald Ramos Perfecto:

dramosp@unmsm.edu.pe

Conflicto de intereses: Los autores declaran no tener conflictos de interés.

Fuente de financiamiento: Autofinanciado. 